\title{
Back to the clinic. Methods I. Research design
of information, more certainty to the answer
}

Juan O. Talavera, ${ }^{*}$ Ivonne Roy-García, ${ }^{2}$ Lino Palacios-Cruz, ${ }^{3}$ Rodolfo Rivas-Ruiz, ${ }^{2}$ Irma Hoyo and Marcela Pérez-Rodríguez²

${ }^{1}$ Directorate of Teaching and Research, Centro Médico ABC; ${ }^{2}$ Instituto Mexicano del Seguro Social, Health Research Coordination, Centro Médico Nacional Siglo XXI, Clinical Research Training Center; 'Instituto Nacional de Psiquiatría "Dr. Ramón de la Fuente", Sub-directorate of Clïnical Research, Department of Clinical Epidemiology; ${ }^{4}$ Department of Internal Medicine, Centro Médico ABC. Mexico City, Mexico

\begin{abstract}
\end{abstract}
Research designs refer to the way information is obtained and are limited by ethical, economic and temporal viability. Research designs are standardized strategies to reduce biases, which in the architectural model of research are identified in the baseline state, the maneuver and the outcome; hence, there are no specific designs for each question. The design with the lowest probability of bias is the clinical trial, followed by cohort and case-control studies and, finally, by cross-sectional surveys. Among the main characteristics that give merit to research designs are the following: population inquiry, which refers to the situation of the population in relation to the clinical course/natural history of the disease; the maneuver, or action that is expected to modify the baseline state, which can be observational or experimental; follow-up, or documented monitoring that is given to each subject, which can be longitudinal or cross-sectional; and directionality, which can prolective or retrolective and refers to the timing of data collection for research purposes. It will always be better having a valuable question, even when answered with a design with higher risk of bias, than a question that is irrelevant or has no applicability.

KEY WORDS: Designs. Inquiry. Assembly. Maneuver. Biases.

\section{Introduction}

There is no specific design for each question. Designs refer to the way information is collected and are determined by ethical, economic and temporal feasibility.

Once the objective and rationale of any research project or article is reviewed, the first section that is addressed is that the of methods, which refers to the research design, a characteristic that allows identifying how the information was or will be collected. ${ }^{1,2}$ Hierarchically, from the highest to the lowest quality of information, there is the clinical trial, followed by the cohort study, the case-control study and, finally, the cross-sectional survey. ${ }^{3}$ Based on these types of research, there are several designs that combine features, such as case-control studies nested within a cohort study ${ }^{4}$ or longitudinal studies, created after cross-sectional surveys, ${ }^{5}$ among many possible cömbinations, there is even the possibility of a cross-sectional survey nested in a cohort.

The different ways of collecting information seek to avoid biases in the different components of the architectural model of research ${ }^{6}$, either at baseline slate, in the maneuver or in the outcome (Figure 1):

- At baseline state, the diagnostic demarcation should be considered, in order to avoid an "inadequate assembly", as well as prognostic demarcation, in order to attenuate the "prognostic susceptibility bias".

- During the maneuver, the quality of the main maneuver, the presence of peripheral maneuvers and the management of adverse events have to
Correspondence:

*Juan O. Talavera

E-mail: jotalaverap@abchospital.com
Date of reception: 15-04-2019

Date of acceptance: 17-05-2019

DOI: 10.24875/GMM.M19000304 


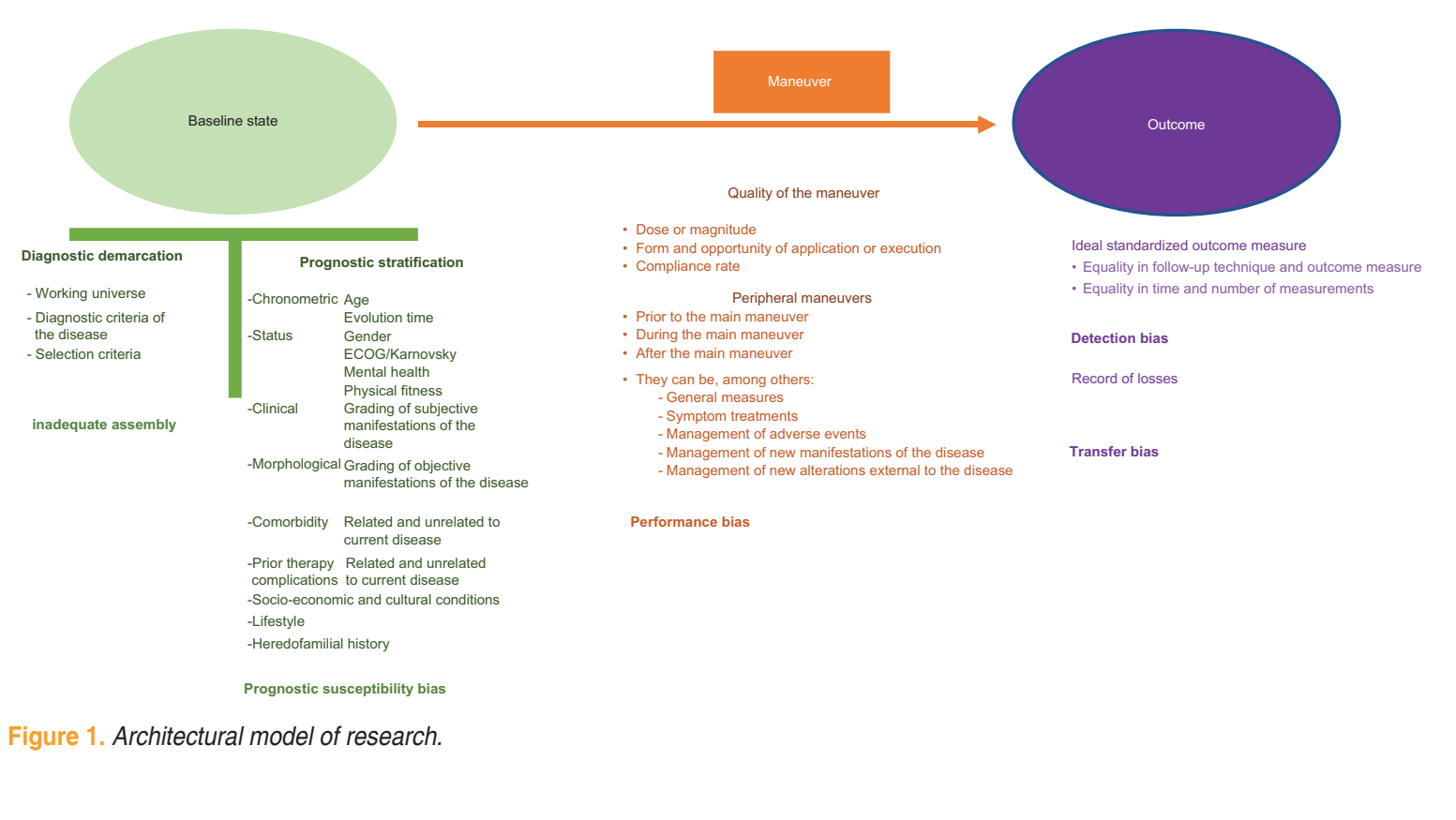

be considered, in order to decrease the "Performance bias".

- An identical outcome measure must be guaranteed in all individuals without distinction, much less dependent on the type of maneuver, as well as equality in times and procedure at each measurement, in order to avoid "detection bias".

- It is necessary to document the losses to follow-up, in order to enable for the evaluation of similarity characteristics between lost subjects and those who continue until the end of the study to be assessed, and this way weighing the presence of "transfer bias".

\section{Research design characteristics (Table 1)}

It should be pointed out that population inquiry is the feature that most determines errors in research designs. population inquiry refers to the moment within the phenomenon of causality where the population candidate to participate is considered. This is how it can be carried out concordant with the baseline state, as it occurs in experimental cohort (clinical trial) or Observational cohort design, or discordant with the baseline state, as it occurs in case-control or cross-sectional survey designs, where the candidate population is sought once the outcome has occurred. While the population inquiry is directed to the universe where all candidates to be assessed come from, the population assembly is made up of those subjects that, having met the health or disease criteria of interest (diagnostic criteria), meet the selection criteria; ${ }^{6}$
Among the other components that are characteristic of research design, we will highlight three:

- Exposure to the maneuver. Is the action expected to modify the baseline condition of the patient producing a change that is known as the-outcome. When the maneuver is assigned as part of the research of interest, it is known as experimental, which characterizes the clinical trial. 7,8 When the maneuver had reasons beyond the investigation for its application and, if this is the case, this previous application is subsequently

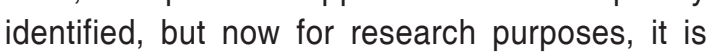
considered an observational maneuver (e.g.: smoking as a self-selected cause and age as cause by action of nature, and even the use $\mathrm{f}$ a drug by recommendation or self-medication). Because of this characteristic, cohort, case-control and cross-sectional survey designs are knowh as observational studies. ${ }^{9,10}$

- Follow-up. It refers to the monitoring giver to each subject with regard to the clinical course or natural history of the disease. A study is recognized as longitudinal when there is real-time documented evidence of each one of the components within the phenomenon of causality, whether recorded or not for research purposes; initially, the baseline state is or should have been recorded, then, as time elapses, the maneuve and, finally, the outcome are. The reasons beyondthe research that might have given origin to the record include medical care, periodic medicaPexamination, etc. ${ }^{11}$ In contrast, the cross-sectional 
Table 1. Research designs main characteristics

\begin{tabular}{|c|c|c|c|c|c|}
\hline $\begin{array}{l}\text { Research } \\
\text { Design }\end{array}$ & $\begin{array}{l}\text { Population } \\
\text { Inquiry }\end{array}$ & Maneuver & $\begin{array}{l}\text { Follow-up } \\
\text { of the } \\
\text { individual }\end{array}$ & $\begin{array}{l}\text { Directionality the } \\
\text { information }\end{array}$ & Description of the characteristic \\
\hline $\begin{array}{l}\text { Clinical trial } \\
\text { (experimental } \\
\text { cohort) }\end{array}$ & $\begin{array}{l}\text { Concurrent to } \\
\text { baseline state } \\
\text { (time 0) }\end{array}$ & Experimental & Longitudinal & Prolective & \multirow{4}{*}{$\begin{array}{l}\text { Research design, the way information is } \\
\text { obtained, "quality of information". } \\
\text { Population inquiry, moment within the cli } \\
\text { course/natural history of the disease in w } \\
\text { the population is sought. } \\
\text { Maneuver, action that is expected to mo } \\
\text { the baseline condition: 1. Experimental, } \\
\text { maneuver assigned for research purpos } \\
\text { 2. Observational, maneuver present by } \\
\text { beyond the investigation (e.g.: by action } \\
\text { nature [age], self-selected [smoking], by } \\
\text { indications [medical care]). } \\
\text { Follow-up refers to the monitoring given } \\
\text { each subject with regard to the clinical c } \\
\text { or natural history of the disease. } \\
\text { 1. Longitudinal, there is documented evi } \\
\text { of baseline state and maneuver prior to } \\
\text { outcome. } 2 \text {. Cross-sectional, the patient } \\
\text { assessed in a stationary form; both base } \\
\text { state and the maneuver, as well as the } \\
\text { outcome are measured in a single time. } \\
\text { Directionality of the information, moment } \\
\text { of information collection for research } \\
\text { purposes; } 1 \text {. Prolective, in real-time, whe } \\
\text { phenomenon is occurring. } 2 \text {. Retrolectiv } \\
\text { information is collected when the phenor } \\
\text { has already occurred. The information co } \\
\text { have been recorded before in real time, } \\
\text { reasons beyond to the investigation. }\end{array}$} \\
\hline $\begin{array}{l}\text { Cohort } \\
\text { (observational } \\
\text { cohort) }\end{array}$ & $\begin{array}{l}\text { Concurrent to } \\
\text { baseline state } \\
\text { (time 0) }\end{array}$ & Observational & $\begin{array}{l}\text { Longitudinal } \\
\text { longitudinal }\end{array}$ & $\begin{array}{l}\text { Prolective } \\
\text { Retrolective (historical) }\end{array}$ & \\
\hline Case-control & $\begin{array}{l}\text { Divergent to } \\
\text { baseline state } \\
\text { (time 3) }\end{array}$ & Observational & $\begin{array}{l}\text { Cross-sectional/ } \\
\text { longitudinal }\end{array}$ & Retrolective & \\
\hline $\begin{array}{l}\text { Cross-sectional } \\
\text { survey }\end{array}$ & $\begin{array}{l}\text { Divergent } \\
\text { to baseline } \\
\text { state (time 3) }\end{array}$ & Observational & $\begin{array}{l}\text { Cross-sectional/ } \\
\text { longitudinal }\end{array}$ & Retrolective & \\
\hline
\end{tabular}

study is when the patient is assessed in a stationary form, with the baseline state and the maneuver, as well the outcome being measured at a single time. At this point, it should be mentioned that even when everything is measured in a single moment and there is no documented evidence of the actual time the facts occurred, artificially reconstructing the real temporality of each section should be tried; for example: in a patient with a five-year history of diabetes in whom studying the damage to a target organ as a result of metabolic control is wanted, his/her baseline state can be rebuilt by asking about his/ her situation five years back, taking into account both the criteria that at the time would have been applied, and his/her baseline characteristics and the metabolic control he/she has experienced since then and until the moment the study is carried out. This way, patients who in the reconstruction of their characteristics were not candidates for entering the study should not be included; similarly, it will be necessary trying to identify at what moment they may have suffered target 


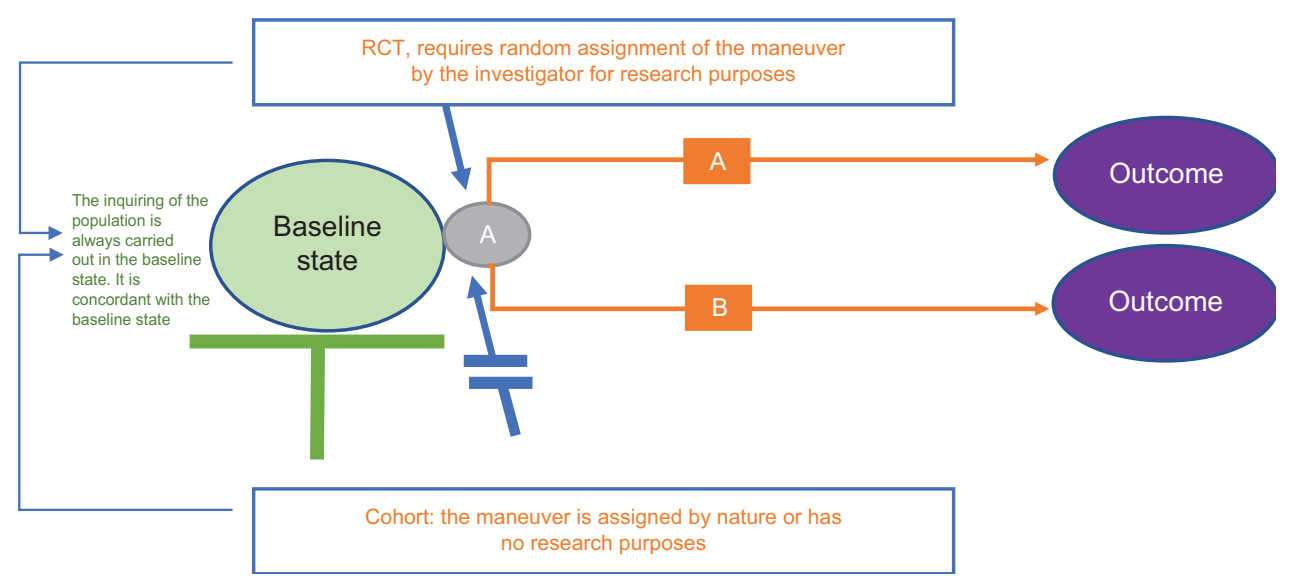

Figure 2. Longitudinal studies design (cohort or randomized clinical trial) and their main biases. $R C T=$ randomized clinical trial, $A=$ random assignment by the investigator.

the moment when the causality phenomenon is occurring. The baseline state is initially documented for research purposes; subsequently the maneuver and, eventually, the outcome are..$^{14} \mathrm{~A}$ study is retrolective when information is collected for research purposes once the causality phenomenon has already occurred; it includes cases where the information was collected in real time -when the phenomenon of causality is occurring- but with purposes unrelated to research, as in medical care or medical examinations. ${ }^{15}$

\section{Research designs ${ }^{16,17}$}

In the clinical trial, also known as experimental cohort, as in the prospective cohort, the collection of information corresponding to the different components of the phenomenon of causality is made in real time and for research purposes. In turn, in historical or retrospective cohorts, the real-time collection of information was carried out for purposes other than research; usually, data collection is made at a given moment with the purpose to provide medical care ${ }^{18}$ or during medical examination, ${ }^{19}$ among others.

As previously mentioned, in these designs there is a concordance between the population inquiry and the assembly of candidates. In the clinical trial, there is assignment of the maneuver for research purposes, while the cohort study only the exposure to the maneuver is measured. In both, follow-up is longitudinal ${ }^{20}$ (Figure 2).

Mistakes are often made, and designs that do not correspond to retrospective or historical cohorts are assumed as such; e.g.: some studies are referred to as cohort studies when they are actually case series because the inquiring the population was carried based on the outcome and, in consequence, it is discordant with the population assembly (the assembly is always made in the baseline state) and only a portion of the original cohort is available, which makes up a population of survivors that corresponds to a survivor case series. ${ }^{21,22}$ If the candidate population is searched in the registry of patients attending for medical care at the moment of the research, allipatients who died or who stopped attending for medical care for any reason within the previous period ${ }^{-b e}$ tween what their baseline state was and the moment at which the investigation is carried out will have been left out. ${ }^{23}$ Overestimation of the prognosis and therapeutic benefits are common problems deriving from this type of designs.

One way to avoid the above-mentioned error and generate a historical cohort is by keeping in mindothe inquiring of the population and its concordance withithe assembly. To this end, it is important to investigate the population in a previous date in order for the quantified years so far correspond to the average follow-up that is wanted for said cohort; i.e., if studying the incidence of target organ damage in diabetic subjects at 10 years of evolution is wanted, instead of looking for them in current patient records (2019), it will be necessary looking for them in the admission records of newly diagnosed patients 10 years back (2009). Once these patients are identified, the causality phenomenon is reconstructed, starting with the assembly, prognostic stratification, the maneuver and peripheral maneuvers, and so on successively until arriving to the outcome. This way, patients who died or were lost to follow-up may be identified, and the condition they were af on their last assessment will be known, which are events 


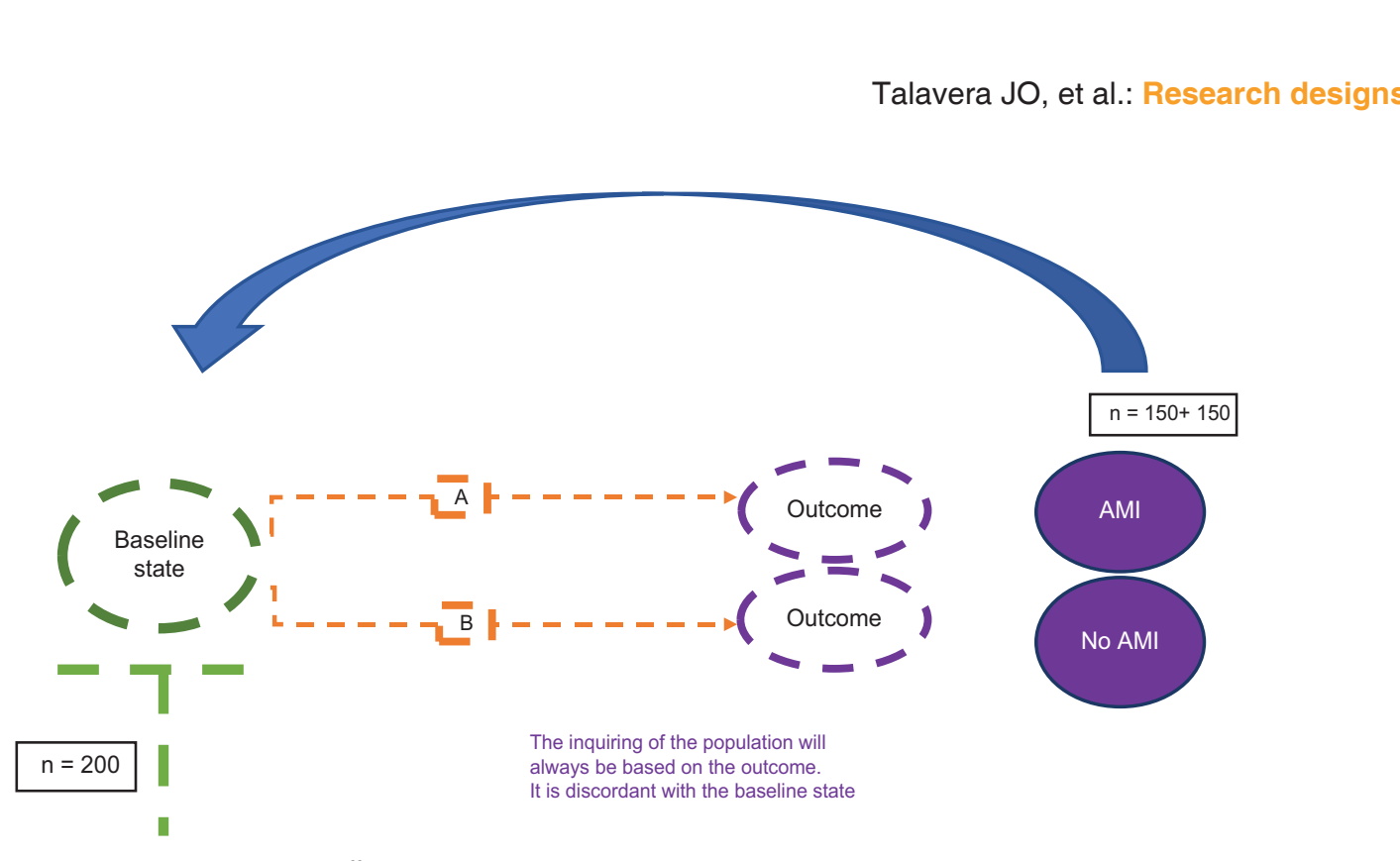

Figure 3. Case-control study. Inquiring only offers the candidate population; subsequently, this population has to be assessed according fo the logical thinking of causality, i.e., it starts from the baseline state towards the outcome. The selection criteria are applied at the baseline state, just as the architectural design is constructed, and those cases and controls not included (not selected) must be replaced in number until reaching the sample size.

that are unknown when a case series that only includes survivors is wrongly regarded as a cohort. ${ }^{24}$

\section{Case-control study ${ }^{25}$}

The case-control study, as its name indicates, carries out the inquiring of the candidate population based on the outcome, where a group of cases (subjects already with the outcome) and a group of controls (subjects without the outcome) are selected; therefore, it is a retrospective compilation of information for research purposes, ${ }^{26.27}$ even when there is the possibility that such information has been collected in real time, but for purposes unrelated to research (medical record, vaccination card and medical examination, among other sources).

Subsequently, the timing of the causality phenomenon occurrence is artificially reconstructed. That is, once the candidate population is identified, although artificially, the reconstruction of the causality phenomenon is made either through some existing record or patient or family member recollection, with the selection criteria being assessed at the moment at which the baseline state temporarily existed (which, as in previous example, could have been 10 years back) and, similarly, exposure to the maneuver at the subsequent corresponding moment and so on until the assessment of the outcome is reconstructed. This way, rebuilding the timing of the real phenomenon, although artificially, is attempted; the inquiring of the population is often mixed up with its assembly, and the selection criteria are wrongly applied at the moment of inquiring of the population and, in consequence, the principles of causality are broken. We should not forget that while the inquiring of the population in the case-control study is in the outcome, the assembly is made at that which was the baseline state (Figure 3).

The fact that the inquiring is carried out at the time of the outcome results in the use of a population of survivors and often from a non-specific origin -survivors may come from different populations of origin-. Although there may be biases of different magnitude due the quality of the information in the reconstruction of events that occurred some time ago (it will always be better if it comes from a medical record than from recall), the existence of transfer bias can never be avoided, which will depend on mobility and mortality of the population where the study subjects corresponding to the group of survivors come from. ${ }^{28}$

\section{Cross-sectional survey ${ }^{31}$}

In the cross-sectional survey, the inquiring of the population (as in the case-control study) is made when there is the possibility of finding subjects with the outcome of interest, even when a population is being not looked for specifically by the presence or absence of the outcome. In this case, there will be subjects with the outcome according to its prevalence in said population. In the cross-sectional survey, subjects can be found at any stage of the causality phenomenon; 


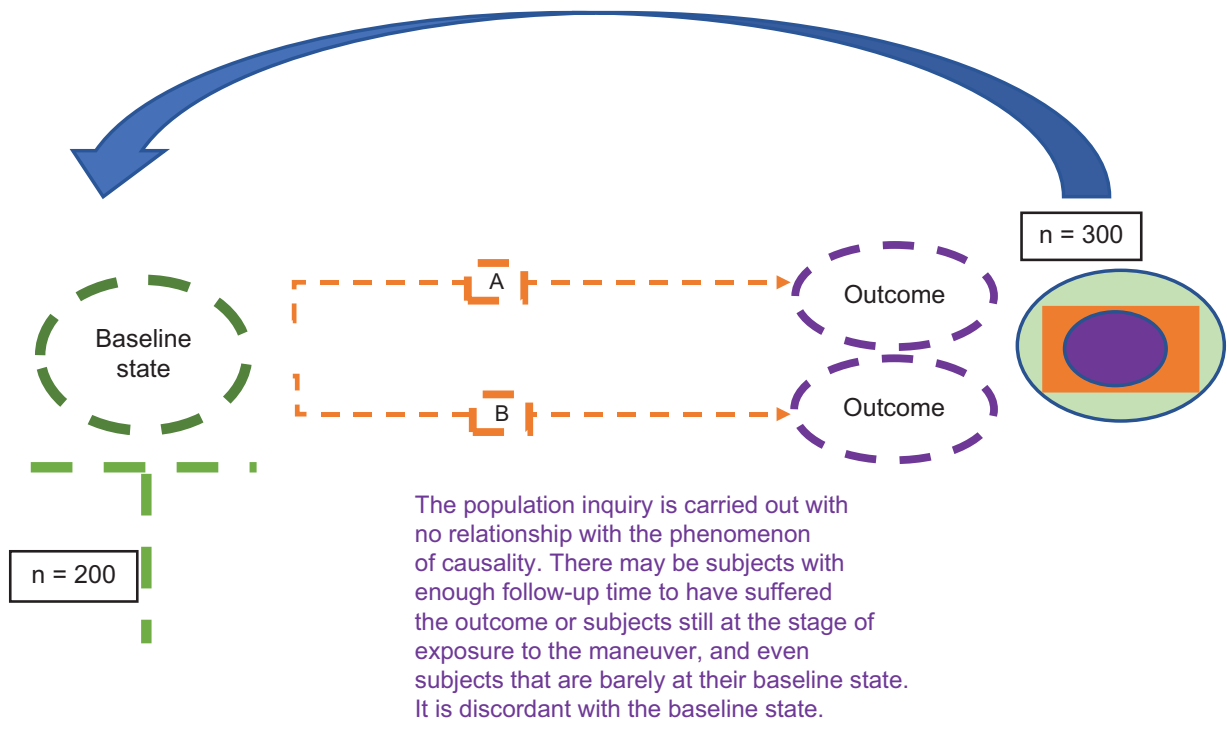

Figure 4. Cross-sectional survey. Screening only offers the candidate population; subsequently, this population has to be assessed following the logical thinking of causality, i.e., starting from the baseline state towards the outcome. The selection criteria are applied at the baseline state, just as the architectural model is constructed, and subjects not included (not selected) must be replaced in number until reaching the sample size.

i.e., there will be subjects whose clinical evolution or natural history of the disease is located in a time at which the outcome can exist and, consequently, subjects will be found with and without the outcome, while others will be found in the period of exposure to the maneuver and others perhaps at the beginning of the baseline condition of interest (Figure 4).

By artificially reconstructing the phenomenon of causality, the research goes back in time to obtain information on the baseline state, the maneuver and the outcome, just as described for the case-control study. As in the latter, included subjects can come from multiple populations and, again, they are only survivors; consequently, there is the risk of transfer bias. Sometimes, cross-sectional survey studies are referred to without the purpose of making comparisons thinking that biases are avoided; however, it would be necessary to establish the moment at which clinical evolution or natural history of the disease the individuals are found in and differentiate those at their baseline state from those at the stage of exposure to the maneuver or at the outcome. There is no way to avoid transfer bias. ${ }^{32}$

\section{Conclusions}

Research designs describe the way to collect information; there is no specific design for each research question. The design preserves the structure of causal thinking, which in turn is approached through the architectural model of research.
The same question can be answered by any of the designs. Prospective designs with inquiring at baseline state -clinical trial and prospective cohort- are the ones with the highest information quality; however, êconomic, ethical and time limitations often force to čonsider retrospective designs. Within the latter, the historical cohort (whose inquiring takes place at basetine state) is the best, since it reduces the transfer biases that are characteristic of retrospective designs where the inquiring is discordant with the baseline state (case-control study and cross-sectional survey).

It will always be better having a valuable question, even when it is answered with a design of lower quality, than having an irrelevant question answered with a higher quality design. That which has no relevance or applicability, doesn't make sense in clinical research.

\section{References}

1. Talavera JO. Research designs. Rev Med Inst Mex Seguro Soc. 2013;51:S10-S15

2. Hernández-Sampieri R. Metodología de la investigación. Méxice: McGraw Hill; 2014.

3. Murad MH, Asi N, Alsawas M, Alahdab F. New evidence pyramidevevid Based Med. 2016;21:125-127.

4. Ernster VL. Nested case-control studies. Prev Med. 1994;23:587-590

5. Rivas-Ruiz R, Clark P, Talavera JO, Huitrón G, Tamayo JA, Salmerón J. Bone speed of sound throughout lifetime assessed with quantitative ultrasound in a Mexican population. J Clin Densitom. 2015;18:68-75

6. Talavera JO, Wacher-Rodarte NH, Rivas-Ruiz R. Investigación clínica III. Estudios de causalidad. Rev Med Inst Mex Seguro Soc. 2011;49:289-294.

7. ASCEND Study Collaborative Group, Bowman L, Mafham M, Wallendszus K, Stevens W, Buck G, et al. Effects of n-3 fatty acid supplements in diabetes mellitus. N Engl J Med. 2018;379:1540-1550.

8. Salminen $P$, Paajanen $H$, Rautio T, Nordström P, Aarnio M, Rantanèn T, et al. Antibiotic therapy vs appendectomy for treatment of uncomplicated acute appendicitis: the APPAC Randomized Clinical Trial. JAMA. 2015;313:2340-2348. 
9. Méndez-Hernández P, Flores $Y$, Siani C, Lamure M, Dosamantes-Carrasco LD, Halley-Castillo $E$, et al. Physical activity and risk of metabolic syndrome in an urban Mexican cohort. BMC Public Health. 2009;9:276.

10. Diez-Ruiz A, Bueno-Errandonea A, Núñez-Barrio J, Sánchez-Martín I Vrotsou K, Vergara I. Factors associated with frailty in primary care: a prospective cohort study. BMC Geriatr. 2016;28:91.

11. Ventura-Ríos L, Bañuelos-Ramírez D, Hernández-Quiroz-MC Robles-San Román M, Irazoque-Palazuelos F, Goycochea-Robles MV. Patient survival and safety with biologic therapy. Results of the Mexican National Registry Biobadamex 1.0. Reumatol Clin. 2012;8:189-194.

12. Machado AD, Anjos FSND, Domingos MAM, Molina MDCB Marchioni DML, Benseñor IJM, et al. Dietary intake of non-dialysis chronic kidney disease patients: the PROGREDIR study. A cross-sectional study. Sao Paulo Med J. 2018;136:208-215.

13. Perminow G, Brackmann S, Lyckander LG, Franke A, Borthne A Rydning $A$, et al. A characterization in childhood inflammatory bowe disease, a new population-based inception cohort from South-Eastern Norway, 2005-07, showing increased incidence in Crohn's disease. Scand J Gastroenterol. 2009;44:446-456.

14. Gallegos-Carrillo K, Flores YN, Denova-Gutiérrez E, Méndez-Hernández P, Dosamantes-Carrasco LD, Henao-Morán S, et al. Physical activity and reduced risk of depression: results of a longitudinal study of Mexican adults. Health Psychol. 2013;32:609-615.

15. Pacheco NL, Andersen AM, Kamper-Jørgensen M. Preeclampsia and breast cancer: the influence of birth characteristics. Breast. 2015;24:613-617.

16. Talavera JO, Rivas-Ruiz R. Investigación clínica IX. Del juicio clínico al ensayo clínico. Rev Med Inst Mex Seguro Soc. 2013;51:S58-S63.

17. Talavera JO, Rivas-Ruiz R. Investigación clínica X. Del juicio clínico al diseño de cohorte. Rev Med Inst Mex Seguro Soc. 2013;51:S64-S69.

18. Reynoso-Noverón N, Villarreal-Garza C, Soto-Pérez de Celis E Arce-Salinas C, Matus-Santos J, Ramírez-Ugalde MT, et al. Clinical and epidemiological profile of breast cancer in Mexico: results of the Seguro Popular. J Glob Oncol. 2017;3:757-764.

19. Briseño-Bass $P$, Chávez-Pérez R, López-Zendejas M. Prevalence of liver steatosis and its relation to liver function tests and lipid profile in patients at medical check-up. Rev Gastroenterol Mex. 2018;3:S0375-S0906.

20. Cantoral A, Téllez-Rojo MM, Ettinger AS, Hu H, Hernández-Ávila M, Peterson K. Early introduction and cumulative consumption of sugar-sweetened beverages during the pre-school period and risk of obesity at 8-14 years of age. Pediatr Obes. 2016;11:68-74.
21. Cacho-Díaz B, Spínola-Maroño H, Reynoso N, González-Aguilar A, Mohar-Betancourt A. Role of overweight, obesity, and comorbidifies in the prognosis of patients with breast cancer with brain metastases. Clin Breast Cancer. 2019;19:394-398.

22. Espiritu Al, Mesina BVQ, Puerto AAD, Reyes NGD, Damianf LF, Pascual V JLR. Neuromyelitis optica spectrum disorder in a tertianthospital in the Philippines: a case series. Mult Scler Relat Disord. 2019;31: 124-130.

23. Abdelmabood S, Fouda AE, Boujettif F, Mansour A. Treatment duteomes of children with acute lymphoblastic leukemia in a middle-income developing country: high mortalities, early relapses, and poor survival. I Pediatr (Rio J). 2018;S0021-7557:30583-30587.

24. Lepe-Zúñiga JL, Méndez-Cigarroa AO, Jerónimo-López FJ, Hèrnảndez-Orantes JG. [Sobrevida global de pacientes con leucemia aguda en el Hospital de Especialidades Pediátricas de Chiapas, México]. BôfMed Hosp Infant Mex. 2018;75(6):338-351.

25. Talavera JO, Rivas-Ruiz R. From clinical judgment to case-contro design. Rev Med Inst Mex Seguro Soc. 2013;51:S70-S75.

26. Doll R, Hill AB. A study of the aetiology of carcinoma of the lung. BfMed J. 1952;2:1271-1286.

27. Girma S, Fikadu T, Abdisa E. Maternal common mental disorder as predictors of stunting among children aged 6-59 months in western Ethiopia: a case-control study. Int J Pediatr. 2019;2019:4716482.

28. Di Forti M, Quattrone D, Freeman TP, Tripoli G, Gayer-Anderson C, Quigley $\mathrm{H}$, et al. The contribution of cannabis use to variation in the incidence of psychotic disorder across Europe (EU-GEI): a multieentre case-control study. Lancet Psychiatry. 2019;6:427-436.

29. Hodge SE, Subaran RL, Weissman MM, Fyer AJ. Designing case-control studies: decisions about the controls. Am J Psychiatry. 2012:169: 785-789.

30. Blaser L, Hassna H, Hofmann S, Holbro A, Haschke M, Zeller Atet al. Leucopenia associated with metamizole: a case-control study. SWiss Med Wkly. 2017;147:w14438.

31. Talavera JO, Rivas-Ruiz R. From clinical judgment to cross-sectional survey. Rev Med Inst Mex Seguro Soc. 2013;51:S76-S79.

32. Shigdel R, Stubbs B, Sui X, Ernstsen L. Cross-sectional and longitüdinal association of non-exercise estimated cardiorespiratory fitness with depression and anxiety in the general population: the HUNT study. Affect Disord. 2019:252:122-129. 